NISTIR 7437

\title{
Demonstration of Real-Time Tactical Decision Aid Displays
}

\author{
William D. Davis \\ David Holmberg \\ Paul Reneke \\ Lori Brassell \\ Robert Vettori
}



NISTIR 7437

\section{Demonstration of Real-Time Tactical Decision Aid Displays}

William D. Davis David Holmberg Paul Reneke Lori Brassell Robert Vettori

Building and Fire Research Laboratory Gaithersburg, Maryland 20899

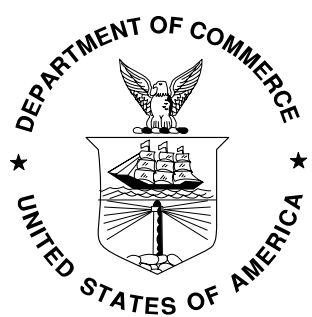

U.S. DEPARTMENT OF COMMERCE Carlos M. Gutierrez, Secretary TECHNOLOGY ADMINISTRATION Under Secretary of Commerce for Technology NATIONAL INSTITUTE OF STANDARDS AND TECHNOLOGY William A. Jeffrey, Director 



\section{Table of Contents}

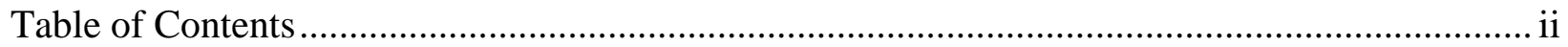

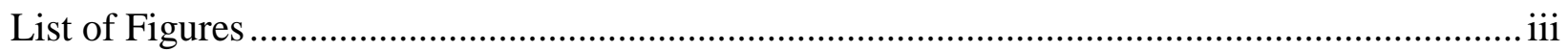

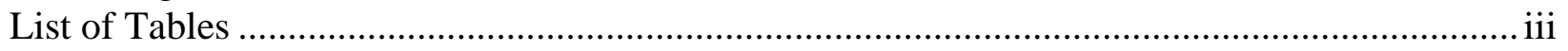

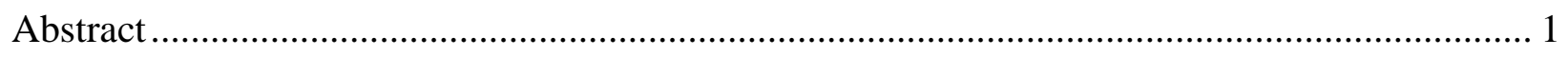

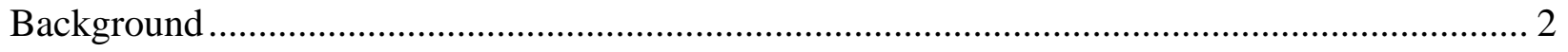

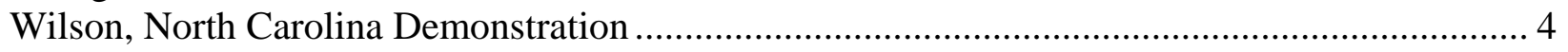

Wireless Information Transmission .............................................................................. 5

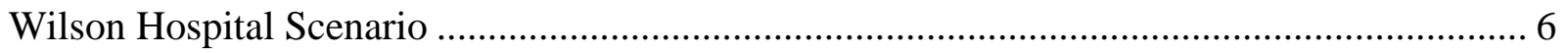

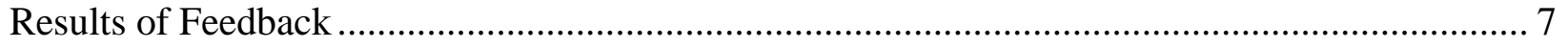

General Comments on the Interface ........................................................................... 7

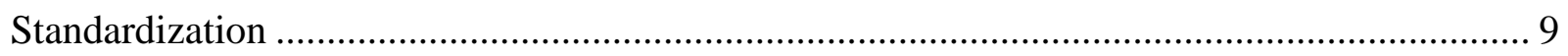

Display Screens and Information Overload.................................................................... 10

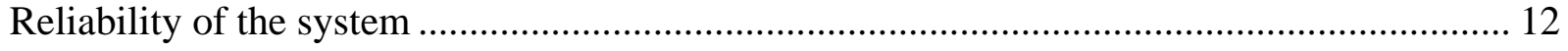

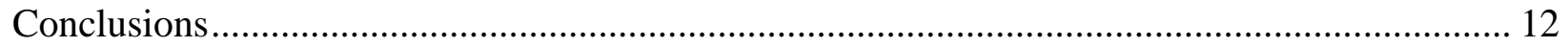

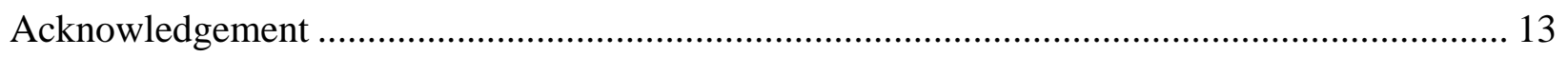

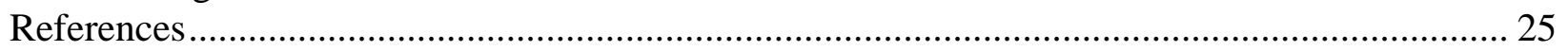




\section{List of Figures}

Figure 1 "En Route" screen for the hospital fire scenario. ........................................................... 15

Figure 2 "On Site" screen for the hospital fire scenario. This screen depicts the first floor plan of the hospital..................................................................................................... 16

Figure 3 "On Site" screen for the hospital scenario, first floor plan zoomed in............................ 17

Figure 4 "On Site" screen for the hospital fire scenario, legend button activated......................... 18

Figure 5 "On Site" screen on the hospital scenario, third floor plan............................................... 19

Figure 6 "On Site" screen of the hospital scenario, third floor plan zoomed in........................... 20

Figure 7 "On Site" screen of the hospital scenario, third floor plan zoomed in, showing interior standpipe locations in the stairwells. …………….................................................. 21

Figure 8 "On Site" screen of the hospital scenario, third floor plan zoomed in, showing interior standpipe locations in the stairwells, and location of electrical utilities.............. 22

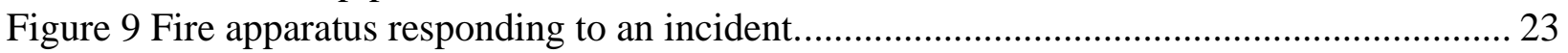

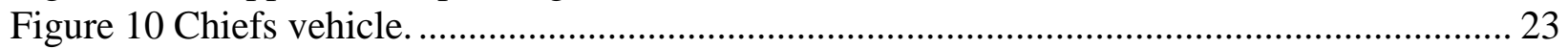

Figure 11 Interior view of incident command vehicle................................................................. 24

Figure 12 Fire Fighters at a remote location from the incident accessing incident

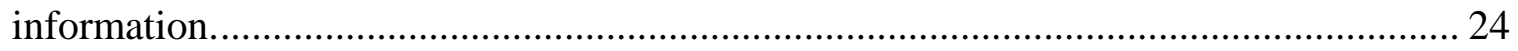

\section{List of Tables}

Table 1 Event list for a Fire in a Hospital Waiting Room scenario............................................... 14 


\section{Abstract}

On September 22, 2005 the National Institute of Standards and Technology (NIST) conducted a demonstration of two prototype tactical decision aid computer interfaces in the city of Wilson, North Carolina. Members of the City of Wilson Fire Department, Wilson Memorial Hospital, Honeywell Inc, and NIST participated in the demonstration. Sensor and other building information from a simulated fire on a third floor wing of the hospital were displayed in realtime on the Honeywell ONYX FIRSTVISION ${ }^{1}$ fire panel and on laptop computers positioned in the hospital, on a fire truck, in the Wilson fire command van and at a Wilson fire station. The objective was to have the members of the Wilson Fire Department evaluate the first responder information displays using a simulated real-time incident. The displays are designed to provide real-time building and emergency information to emergency responders, incident command, and dispatch centers. The concept of transmitting real-time building information to emergency responders was well received. The participants concerns with these systems centered on standardization, information overload, and reliability.

Transmission of real-time building information from a laptop computer located at the Wilson hospital to a laptop computer located in a fire truck, and laptop computer located at the Wilson fire station using a cellular connection was tested. The XML format worked well with no observable degradation in the received information content.

The evaluations and recommendations suggested by the participants for improvements of the current displays are presented in this document.

Key Words: building information, elevators, emergency preparedness, emergency responder, emergency response, fire alarm system, fire detection, homeland security, incident command

\footnotetext{
${ }^{1}$ Certain commercial equipment, instruments, or materials are identified in this paper in order to adequately specify the experimental procedure. Such identification does not imply recommendation or endorsement by the National Institute of Standards and Technology, nor does it imply that the materials or equipment identified are necessarily the best available for the purpose.
} 


\section{Background}

Many large buildings have building automation systems that manage environmental systems, security systems, fire protection systems, energy management systems, elevator systems, etc. These systems process and store a large amount of data that is potentially useful to emergency responders. Such data would include floor plans of the building, sensor data from smoke and heat detectors, gas detectors, motion detectors, etc. Other information may include data from heating ventilation and air conditioning (HVAC) systems, door and elevator access, room occupancy, lights, and cameras. Yet, for the most part, all this information is bottled up in the building even while it could provide tremendous situational awareness to those outside the building.

This building information needs to be sent to and displayed on a wide variety of display devices, from high-resolution screens at dispatch centers, wireless devices for notebook computers in fire apparatus or police cars, and handheld devices. In order to assure interoperability of the information (or data) transmissions, requirements for the data and presentation formats must be defined as well. In the building industry, there is ongoing work to address building controls interoperability between different manufacturers, including the work on the Building Automation and Control Networks (BACnet) standard at NIST [1], and more recently work to provide building data to those outside the building. In the case of an emergency event, fire, police, and other emergency personnel arrive at a building and are faced with the need to quickly appraise the situation, find occupants, locate problems, determine the best way of dealing with the emergency, deploy resources, and then update tactical information as the event progresses.

Recently, there has been a focused effort to improve prevention, preparedness, response, recovery, mitigation, and coordination processes across the country. However, a comprehensive approach to providing building tactical information to building incident responders, applicable at all jurisdictional levels and across functional disciplines, would further improve the effectiveness of emergency response providers and incident management organizations across a full spectrum of potential building incidents and hazard scenarios. Such an approach would aid in coordination and cooperation between public and private entities in a variety of domestic incident management activities.

On May 3, 2004, NIST conducted a workshop to identify information needs for emergency responders during building emergencies [2]. That workshop brought together emergency responders with the goal of sharing the vision of how the availability of building information can impact emergency response, what specific building information would be of greatest benefit to public safety officials, how to present it, and with what security measures. The workshop included representatives from the police, fire, medical, building technology, government, and security communities.

To set the stage for this workshop, NIST prepared a draft white paper on the issues of specific building information needed by emergency responders. The information contained in the draft white paper was based on material from the National Fire Protection Association Standard 1620 Recommended Practice for Pre-Incident Planning [3], pre fire plan information from publications (online and print) and fire departments, and discussions with individual local first 
responders. Information was also used from a meeting of Chief Officers of Fire and Police to discuss the need and potential use of building information in emergency response, held in July of 2003 at NIST.

On July 26, 2005 NIST conducted a second workshop on information needs for emergency responders [4]. For this second workshop the attendees worked with laptop computer interfaces and evaluated the presentation of emergency information on four different scenarios that require Fire Department and or Police response. The four scenarios were: (1) a fire in a hospital, (2) a person breaking into a laboratory building and setting fire to a room on the third floor, (3) a fire on the second floor of a two story single family dwelling, and (4) an emergency medical call inside a large shopping mall. The displays were presented on laptops since these are similar to the equipment that is currently installed in some fire department apparatus and incident command vehicles.

Based on the initial work developing the White Paper, and the results from the first responder workshop the need for both an "En Route" screen and an "On-site" screen became evident. As envisioned the "En Route" screen would give a plan view of the building footprint and surrounding area. Streets that surround the building would be indicated along with information such as location of fire hydrants, fire department connections to the building standpipe and automatic sprinkler systems, and location of entrances to the building. Other information that may be displayed would be the location of interior stairwells, elevators, and an indication if hazardous materials are present in the building. The second screen, titled "On Site" would give detailed information regarding the interior of the building. Information from pertinent building systems, output from decision support systems, and location of stairs, standpipe, and a variety of other static building information would be available for display on this screen.

The attendees were asked to run through each scenario multiple times to determine what information was available and to get comfortable with the way the information was presented. They were asked to evaluate the interface by noting:

- What worked?

- What did not work?

- Was the information useful?

- What other information would you need that was not provided?

- What is missing?

- Was the layout acceptable?

- How could the interface be improved?

- What other scenarios might demand other kinds of information or different interface design?

- If you have a system such as this, how would it impact your operations in the field, at the emergency dispatch center?

- What additional work load would be added to your incident command operations in the field?

- What additional training would be required of your field personnel and your emergency dispatch center personnel?

- What questions do you have that have not been addressed? 
Suggestions for improvements on the information and how it was displayed from this workshop were incorporated into both the "En Route" and "On Site” screens used in the Wilson, North Carolina demonstration.

\section{Wilson, North Carolina Demonstration}

An evaluation/demonstration of two prototype NIST tactical decision aid computer interfaces and the Honeywell ONYX FIRSTVISION by Notifier ${ }^{2}$ fire panel was conducted in the city of Wilson, North Carolina on September 22, 2005. Members of the City of Wilson Fire Department, Wilson Memorial Hospital, Honeywell Inc, and NIST participated in the demonstration. The demonstration was divided into three distinct parts. The first consisted of representatives of NIST and Honeywell going over and explaining the operation of their respective displays to the fire department personnel participating in the demonstration. The various display screens and the meanings of the icons used in the displays along with the various colors used to depict room conditions were explained. For the second part of the demonstration, fire department personnel went to their respective fire apparatus, command van, or remote location and simulated a response to the building incident based on information available to them from the laptop displays and when at the building the Honeywell fire panel. The Honeywell fire panel display was also evaluated in the command van. The third and final part of the demonstration consisted of assembling all participating personnel back into the classroom and asking for their feed back, recommendation and suggestions on improving these types of information systems.

For this demonstration, both the NIST and Honeywell displays used the same preprogrammed virtual fire incident. The NIST display used two different formats or screens to present the building information. An example of the first screen, titled "En Route" is shown in Figure 1. This screen gave a plan view of the building footprint and surrounding area. Streets that surround the building were indicated along with information such as location of fire hydrants, fire department connections to the building standpipe and automatic sprinkler systems, and location of entrances to the building. Other information that may be displayed would be the location of interior stairwells, elevators, and an indication if hazardous materials are present in the building. The top portion of this screen gives additional information on the building and incident. Information may include the building name and address, location of the fire within the building, estimate of how long the fire has been burning, building occupancy, is the building sprinklered, etc. A "N/A" indicates that information is either not available or does not pertain to the incident. The button in the upper left hand portion of the screen labeled "On Site Screen" allowed the user to toggle back and forth between this "En Route" screen and the "On Site" screen which is shown in Figure 2. This figure depicts the floor plans of the building, in this case the first floor of the hospital. The red buttons along the top of the screen give the user access to various types of building information. A brief description of the type of information that may be accessible from each button follows:

\footnotetext{
${ }^{2}$ Certain commercial equipment, instruments, or materials are identified in this paper in order to adequately specify the experimental procedure. Such identification does not imply recommendation or endorsement by the National Institute of Standards and Technology, nor does it imply that the materials or equipment identified are necessarily the best available for the purpose.
} 
- $\quad$ Security - Information from security sensors, occupancy sensors, location of individuals needing assistance, etc.

- Elevators - Number and location of elevators. What floor is the elevator on? What is its mode of operation? Is there smoke in the elevator shaft etc.?

- $\quad$ Fire Fighting Equipment - Location of any fire fighting equipment that may be stored in the building for use by the fire department, location of automatic external defibrillators, location of fire extinguishers, etc.

- Utilities - Location of main gas, electric, water shutoffs. Location of utility shut offs for individual floors, areas, etc.

- $\quad$ Building Generator - Information on building generator.

- $\quad$ Fire Walls - Location and ratings of fire walls.

- $\quad$ Standpipes - Location of interior fire department stand pipe connections.

- Hazardous Materials - Location of hazardous materials within the building. Links to information regarding specific hazardous materials, etc.

- $\quad$ Building Hazards - Information of potential hazards to emergency responders.

- Valuable Materials - Location of extremely valuable material.

Along the right side of the screen it can be seen that the user is viewing the first floor of a three floor building. Below this are two buttons that allow the user to navigate to the other floors. Below these are a set of navigation buttons that allow the user to zoom in and out of the floor plan and pan the floor plan in the event it is to large to fit on one screen. Finally the reset button at the bottom allows the user to quickly reset the floor plan to a default view.

Along the bottom left of the screen is the "En Route" button which allows the user as it states to toggle back and forth between this "On Site" screen and the "En-Route" screen. The next button over, titled "Building Info" will bring up the same building information as found on the "En Route" screen. The "Event List" button will show all changes in building sensors and room conditions of interest. For example, if a detector is activated the event list would indicate the location, time, and type of detector that has activated. On the floor plan the appropriate icon indicating the type of detector would now be shown in the appropriate location on the floor plan. The "Legend Button" gives information on the different icons that are used.

It should be remembered that the two screens presented here for this demonstration were developed by NIST as part of a research project to help develop standards and to determine the wants and needs of the fire service. NIST considers the recommendations for the displays as preliminary, and knows that there will be different applications that might present all or parts of this information in different ways.

\section{Wireless Information Transmission}

A laptop computer with cellular phone cards operating at $2.4 \mathrm{GHz}$ was placed in the communication center of the Wilson Memorial Hospital. The purpose of this computer was to broadcast real-time building information wirelessly out to similarly equipped laptop computers that were placed in fire apparatus, a fire department command vehicle, the 9-1-1 emergency 
dispatch center, and a fire station. This method was tested prior to the demonstration by transmitting from the hospital to a fire apparatus at the Wilson fire station. The wireless transmission consisted of an XML data stream generated using a publish-subscribe server. The XML data stream carried the real-time information generated by the building sensors and systems. The static data that would include floor plans, building outline, building content and other time insensitive information was stored on the computer hard drives. Only changes of state of the building sensors and systems were sent which minimized the size of the required information packet. The technique worked well during the test but failed during the demonstration when the server was connected to multiple locations. The failure of the server to make multiple connections to clients is a software problem that is resolvable.

\section{Wilson Hospital Scenario}

The scenario depicts a fire that has started in the third floor waiting room of a hospital. Figure 1 shows the "En Route" screen. The circle with the black dot located near the left side of the hospital building outline gives an approximate location of the initiating alarm. On the actual computer screen this icon would be flashing. Figure 2 shows the "On Site" screen. This figure depicts the first floor plan of the hospital. Only major areas of the floor are indicated in this figure. In order to get a more detailed view of the floor the user would zoom in one level. Figure 3 shows the first floor plan after the user has zoomed in one level. Here all the rooms are now labeled. Figure 4 shows the first floor plan after the user has pressed the "Legend" button. A box appears which gives a description of the various icons used. Since the incident is on the third floor of the hospital the user has the buttons on the right side of the screen to bring up the third floor plan view which is shown in Figure 5. Figure 6 is the third floor plan again zoomed in. As the incident progresses real time information from the building sensors and systems is sent to the emergency responders. This screen, Figure 6, shows the time within the scenario in which alarms have been received from ten different rooms, indicated by the red circle in the center of each room. The room of origin, the waiting room, is now shown in yellow. This would indicate that the room has reached a possible toxic/thermal hazard. The five rooms in green indicate that these rooms have sufficient smoke to possibly cause limited visibility conditions. For Figure 7 the user has pressed the button along the top marked "Standpipes". As can be seen in the figure, each stairwell has an icon that indicates the presence of an interior fire department standpipe connection. In Figure 8 the user has now pressed the button marked "Utilities". In this case icons indicate that there are electrical shut offs located in rooms 32 and 37. Room 32 is next to the waiting room where our simulated fire started.

All of these screens would be available to responding fire, police, emergency medical service apparatus, emergency dispatch center, and any other remote site deemed necessary. Different individuals with different operational needs can access the piece of information that they need at any particular time during the incident that will help them perform their assigned task. An officer in a fire apparatus, Figure 9 may have different informational needs than a responding chief, Figure 10. Additionally, the environment in which the information is obtained is radically different. An officer in a fire apparatus usually has 5 minutes or less between the time that the alarm is received and the fire apparatus reaches the scene. The officer must perform a myriad of tasks while responding to the incident such as donning protective clothing, verifying the route, checking his crew, etc., which may reduce the amount of time available to study the En Route 
screen to only a minute or two. A fire chief, like a police officer, may be driving the vehicle and only have a few seconds before starting the response to obtain information. An individual at a 91-1 emergency dispatch center, a command vehicle Figure 11, or some remote site Figure 12, may have a quieter and less chaotic environment in which to obtain information with additional time to look at the On-site screen before the fire apparatus arrives.

\section{Results of Feedback}

\section{General Comments on the Interface}

- A clear bold indication of where the initial event is. We must be able to direct companies to the correct entrance, to the correct building stairwell and standpipe for the alarm in question.

- Differentiate the initial alarm or detector activation from later detector activations.

- Indicate which stairways have access to the alarm area. Which stairways have access to the roof areas?

- Link hazardous materials to a database such as the U.S. Department of Transportation Emergency Response Guidebook or to Material Safety Data Sheets.

- Indicate the location of the building electrical back up generator if there is one.

- Link system to a Geographic Information System so that street names are shown on the “En Route” screen.

- Add a zoom function to the en-route screen.

- Indication of which doors are locked and the location of any key boxes where available.

- For a touch screen the buttons should be big enough for a gloved hand. Some of the fire fighters indicated that they have not found a touch screen that is user friendly in fire apparatus. Trying to chase the button down while responding to an incident is difficult at best. Have the initial screen and information pop up. The officer is going to have to make the most utilization of the first screen as he/she can. Response time is short, fire apparatus is bouncing, the officer is getting his/her protective clothing on, assisting the driver, communicating with other fire fighters in the apparatus, talking on the radio to the emergency dispatch center, etc.

- Once you have arrived at the scene the screens and buttons are ok. 
- Keep the input options open. Possibly touch screen for apparatus, stylus or mouse for command vehicles, emergency dispatch centers, and administrative use.

- A clear indication of the operational mode/status each building elevator is in. What floor are they on? An indication of the conditions just outside the elevator.

- Have the ability to rotate the image on the screen. Have the ability to rotate the building so that the user is always looking at the building from the same angle. For example, the user would always be positioned at the bottom of the screen so the building is rotated so that the side of the building the user is on is always at the bottom of the screen.

- Add a North, South, East, West indicator.

- Fire hydrant and Exterior fire department connections need to be better differentiated, especially if they are located close to each other.

- Indication of which part of the building each fire department connections serves.

- Ability to have information on all the fire suppression systems in the building, standpipes, sprinkler, dry chemical, hood and duct, etc.

- Better symbology to identify building events. Flashing indicators seemed to be the consensus, but keep the symbols small so they do not cover the floor plans.

- Flashing indicators should be minimized to the location of the initial event and current changes. Too many flashing indicators lead to confusion.

- Would like location of building occupants.

- Ability to have a history of the alarms, replay the event.

- Show smoke travel.

- Have the ability to show information from the Heating Ventilation and Air Conditioning (HVAC) systems. Which HVAC system serves which part of the building?

- Note location of firewalls and their ratings.

- It was difficult to determine where you were using the "On Site” screen.

- Being able to orient yourself to the building.

- Within the legend add description of what colors define room conditions.

- Effects of lighting conditions on the computer screen may bleach out subtle symbols. 
- Need the foot print of the entire building for each floor, all in the same orientation, this will reduce disorientation.

- Have the ability to track emergency responders on the floor plans and also any other personnel as needed. Possibility of adding hospital personnel such as hospital security.

\section{Standardization}

There was a concern among all the participants regarding standardization. The consensus was that there should be no new learning curve from each manufacturer. The symbols used need to be standardized. Some comments from the participants follow:

What happens when different companies come up with different bells and whistles, how long will it take to standardize the systems?

I want to look in my fire apparatus at the same screen no matter who makes it.

The system needs to be generic enough so that no matter what company is providing it, the information will fit on the screen.

A big concern we have is that there are so many different companies making the different alarm panels, systems, etc., that whatever this turns out to be in the end, it needs to be generic enough that whatever system is in place in the building, that I am looking at a generic layout and set of information from the building in the same format, a generic style of information. My fear is that in order to create selling points for their system to a client they start adding bells and whistles to make it appealing to the client but to us, the emergency responder, it is information overload and of no use to us, stuff we do not need.

A question was raised about the possibility of configuring the display in the apparatus to get the information you or your department desires from a generic shopping list of information or data that could be provided.

It does not have to be generic to our fire department, but generic to the fire service. My fear is that I do not want to look at a screen from Company A and a different screen for Company B because they have different bells and whistles. 
The menus should be the same for all scenarios, there should not be a different set of buttons for a hazardous material incident compared to a building fire. Need standardization.

The color itself is not important as long as it is standard, symbols need to be standard.

\section{Display Screens and Information Overload}

Discussion regarding the two screens "En Route" and "On Site" centered on who would benefit most from the information presented. The consensus was that the "En Route" screen would be of greatest benefit to the first responding or first arriving apparatus. The "On Site" screen would provide information for incident command staff, other apparatus that may be requested to respond later in the incident or possible to the 9-1-1 emergency dispatch center. An Engine officer, focusing on the NIST display, said he focused on the information he could get in the short amount of time he had from dispatch to arriving on scene. It was useful to know the area or location in the building where the alarm was coming from. Some comments from the participants follows:

The en-route screen can be important to the incoming officer on fire apparatus because it will tell him where to place his apparatus if he knows where the alarm is. Not sure how much the "On Site" screen would be to the officer on the fire apparatus, however for the incident commander, once operations have started and the initial company officers have started to work, the Incident Commander can make tactical decisions, based on information from the "On Site" screen. It becomes valuable as a planning tool at this point.

The time you have from dispatch to arrival, the en route time that you have, and all the information that can be displayed, other than the floor plan and the location of the alarm, much more than that leads to information overload. More detailed information would be more beneficial for command staff. Once the fire apparatus gets on the scene, the officer may interface briefly with the alarm panel in the building, then he is done with it at that time. The command staff can use more of the information.

I focused on the information I could get in the short amount of time from dispatch to arriving on scene. It was useful to know the area in the building where the alarm was coming from. It would be useful if the closest entrance and stairs to the alarm could be highlighted. 
The command staff has time to look at it, but me going down the road in fire apparatus looking at a small computer screen; if the original alarm is flashing I can know to go to the rear instead of the front.

From the 9-1-1 emergency dispatch perspective, we would be worried about information overload. We are already trying to monitor multiple computer screens that are all changing.

The "On Site" is too detailed for fire apparatus riding down the road.

Some of the Fire Department personnel had some encouraging comments to make regarding what was felt as information overload during this demonstration.

The more you use a system like this, the more comfortable you will be. There will be a need for training. For this demonstration more training would have been helpful, but we did not have the time. When you use it day to day, it will be easier; you will know what the symbols and colors mean.

I can see a lot that this can be used for, the first-in apparatus, and incident commander. To be able to see the room of origin, where the problem is located. It may look overwhelming at first, but as you get use to it, it gets better.

Since the response time is relatively short and obtaining information from the computer screen may be difficult or the individual is driving the vehicle and may not be able to access the computer the concept of having the building information sent to a remote location away from the incident was discussed. The remote location could be the emergency dispatch center or some other location such as fire department or police department headquarters where someone could access the information in a much more quiet and non chaotic environment. Here also the monitors could be larger when compared to the small laptop monitors that were available. The general consensus is that this appears to be a good idea and could develop in the future, for now staffing does not allow it. Some comments regarding this concept from the participants as follows.

It would be rare that you would have that situation of a command officer back at the station. Incident command would be at the scene.

It would be nice if you had the ability. Just because you have the technology does not mean you have the ability. 
I do not see the personnel being there to do this. Maybe a very large department can do this. In the future if viable, change or add staffing to accommodate this.

\section{Reliability of the system}

A concern of the participants was the accuracy of the information that was being presented. Questions of who will maintain the accuracy of the static building information and how reliable are predictions using building sensors. Some comments follow.

Some of the information presented will depend on how accurate the premises keeps the information, how often will it be updated.

Concern was expressed about the reliability of the predictions and the reliability of the sensors.

Is what I am seeing accurate; is that what the conditions are really on the floor?

Information needs to be accurate. What the sensor says needs to be accurate or pretty accurate.

Can the detectors tell you if the room is cooling off?

There is always a concern when you are trying to predict off a sensor because a sensor is a spot detector, it tells you what is happening at that spot, but not in the room. An accuracy check or algorithm can be put in the system. Reliability of predictions is important.

\section{Conclusions}

NIST demonstrated the feasibility of transmitting real-time building information from within a building to computers located at remote locations away from the simulated incident scene. The users of the computer interfaces gave feedback to NIST regarding the use of the information. Concerns from the emergency responders who used this system included: standardization of the systems between different manufactures, the possibility of information overload on users of the systems, and the reliability of building and sensor data. A number of issues still need to be resolved. These issues include the fusion of other real-time building system information onto the building publish/subscribe server, enhanced displays that will accommodate multisystem building information while avoiding information overload, refinement of wireless transmission 
to responding apparatus, and developing methods and standards to enable the quick and efficient conversion of building plans to first responder displays.

\section{Acknowledgement}

This workshop was sponsored in part by the Department of Justice Community Oriented Policing Service (COPS) via the NIST Office of Law Enforcement Standards (OLES) to advance the development of the Building Tactical Information System for Public Safety Officials project.

Appreciation is extended to Chief Don Oliver and the personnel of the Wilson North Carolina Fire Department for participating in the demonstration and providing valuable feedback that will be passed on to standard making organizations.

Appreciation is extended to Hilton Best, James White, and Rob Boswell of Wilson Memorial Hospital, Wilson N. C. for providing access to the hospital and support for this demonstration.

To Andrew Berezowski, Michelle Raymond, and David Tamulevich from the Honeywell Company for participating in the demonstration and providing the ONYX FIRSTVISION fire panel for evaluation. 
Table 1 Event list for a Fire in a Hospital Waiting Room scenario.

Event Time Description of event

\begin{tabular}{|c|c|}
\hline 11:02:56 PM & Heat sensor activated - level 3 waiting room \\
\hline 11:05:11 PM & Heat sensor activated - room 379 \\
\hline 11:06:11 PM & Potential hazard - level 3 waiting room \\
\hline 11:06:42 PM & Visibility limited - level 3 waiting room \\
\hline 11:07:30 PM & Toxic/thermal hazard - level 3 waiting room \\
\hline 11:08:47 PM & Visibility limited - level 3 EENT room \\
\hline 11:08:48 PM & Visibility limited - room 374 \\
\hline 11:09:19 PM & Visibility limited - room 376 \\
\hline 11:09:20 PM & Visibility limited - room 378 \\
\hline 11:09:21 PM & Visibility limited - room 380 \\
\hline 11:09:22 PM & Visibility limited - room 382 \\
\hline 11:09:23 PM & Visibility limited - room 384 \\
\hline 11:09:24 PM & Visibility limited - room 375 \\
\hline 11:09:25 PM & Visibility limited - room 377 \\
\hline 11:09:26 PM & Visibility limited - room 379 \\
\hline 11:09:27 PM & Visibility limited - room 381 \\
\hline 11:09:51 PM & Visibility limited - room 383 \\
\hline 11:09:52 PM & Visibility limited - room 385 \\
\hline 11:09:53 PM & Visibility limited - section E-3 \\
\hline 11:09:54 PM & Visibility limited - section D-3 \\
\hline 11:10:10 PM & Visibility limited - room 313 \\
\hline 11:10:55 PM & Toxic/thermal hazard - level 3 EENT room \\
\hline 11:10:56 PM & Toxic/thermal hazard - room 374 \\
\hline 11:10:57 PM & Toxic/thermal hazard - room 376 \\
\hline 11:10:58 PM & Toxic/thermal hazard - room 378 \\
\hline 11:11:22 PM & Toxic/thermal hazard - room 380 \\
\hline 11:11:23 PM & Toxic/thermal hazard - room 382 \\
\hline 11:11:24 PM & Toxic/thermal hazard - room 384 \\
\hline 11:11:25 PM & Toxic/thermal hazard - room 375 \\
\hline $11: 11: 26$ PM & Toxic/thermal hazard - room 377 \\
\hline $11: 11: 27 \mathrm{PM}$ & Toxic/thermal hazard - room 379 \\
\hline 11:11:28 PM & Toxic/thermal hazard - room 381 \\
\hline $11: 11: 29$ PM & Toxic/thermal hazard - room 383 \\
\hline 11:11:51 PM & Toxic/thermal hazard - room 385 \\
\hline 11:11:52 PM & Toxic/thermal hazard - room 313 \\
\hline 11:11:53 PM & Visibility limited - section B-3 \\
\hline 11:11:54 PM & Flashover conditions - level 3 waiting room \\
\hline 11:12:19 PM & Visibility limited - room 323 \\
\hline 11:13:09 PM & Visibility limited - room 303 \\
\hline 11:13:10 PM & Toxic/thermal hazard - room 313 \\
\hline 11:13:19 PM & Visibility limited - section A-3 \\
\hline 11:14:09 PM & Visibility limited - section E-3 \\
\hline 11:14:10 PM & Visibility limited - room 386 \\
\hline 11:14:11 PM & Visibility limited - room 387 \\
\hline 11:14:12 PM & Visibility limited - section B-3 \\
\hline
\end{tabular}




\section{Wilson Hospital}

Fire - N/A probability - Floor N/A - Fire size: N/A - Water needed: N/A gal/min

Building - occupied - 3 story hospital - no sprinklers - type $V$

Stage - No Police - No

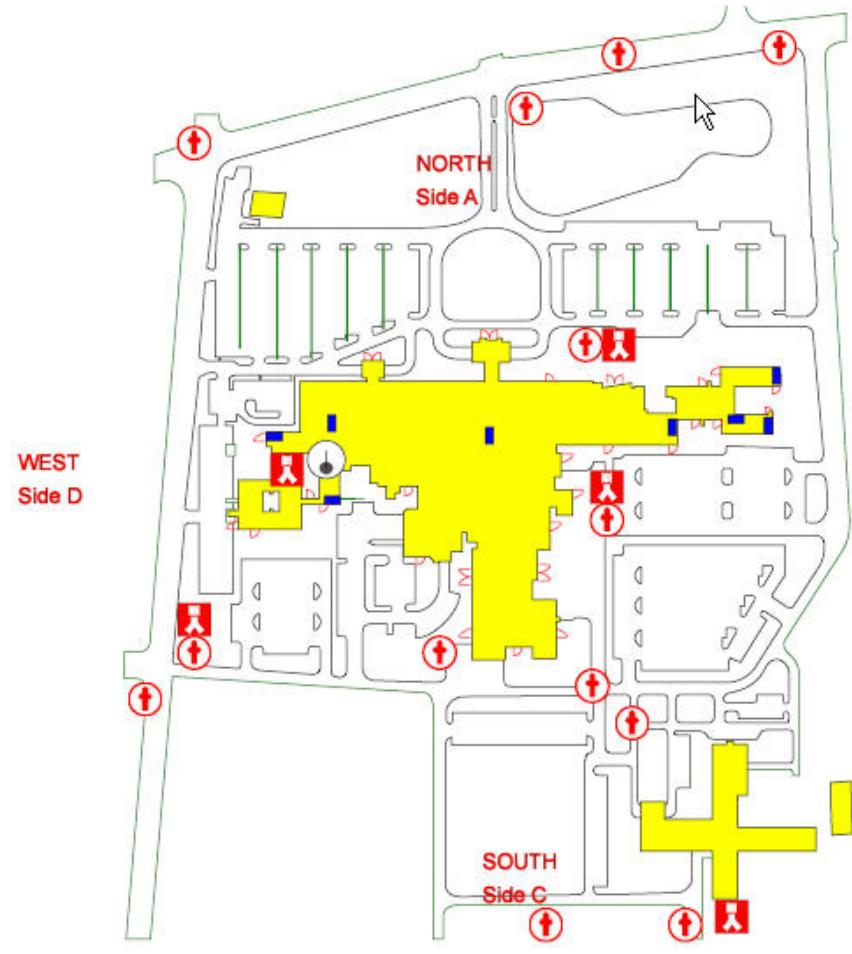

Figure 1 "En Route" screen for the hospital fire scenario. 


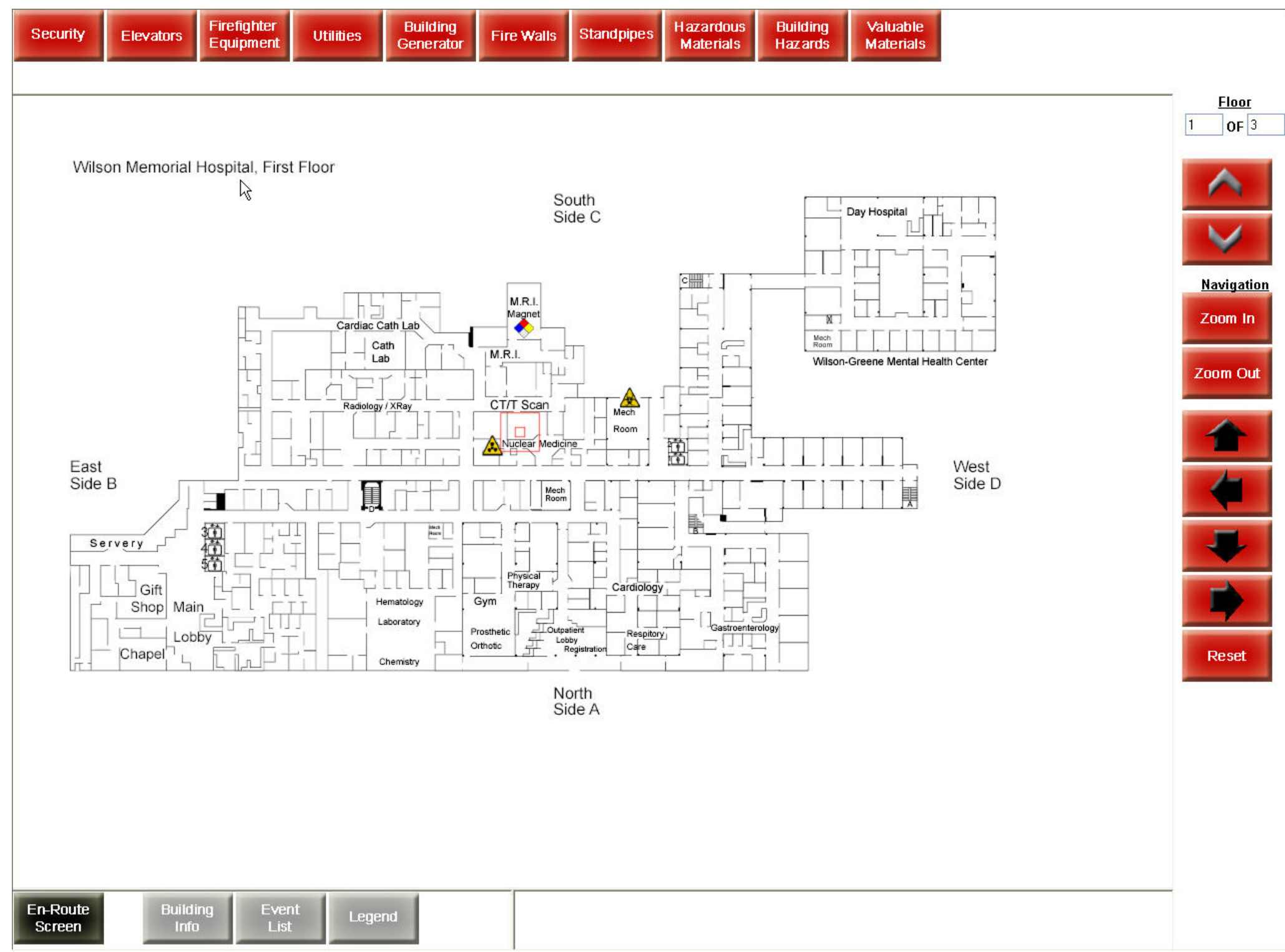

Figure 2 "On Site" screen for the hospital fire scenario. This screen depicts the first floor plan of the hospital. 


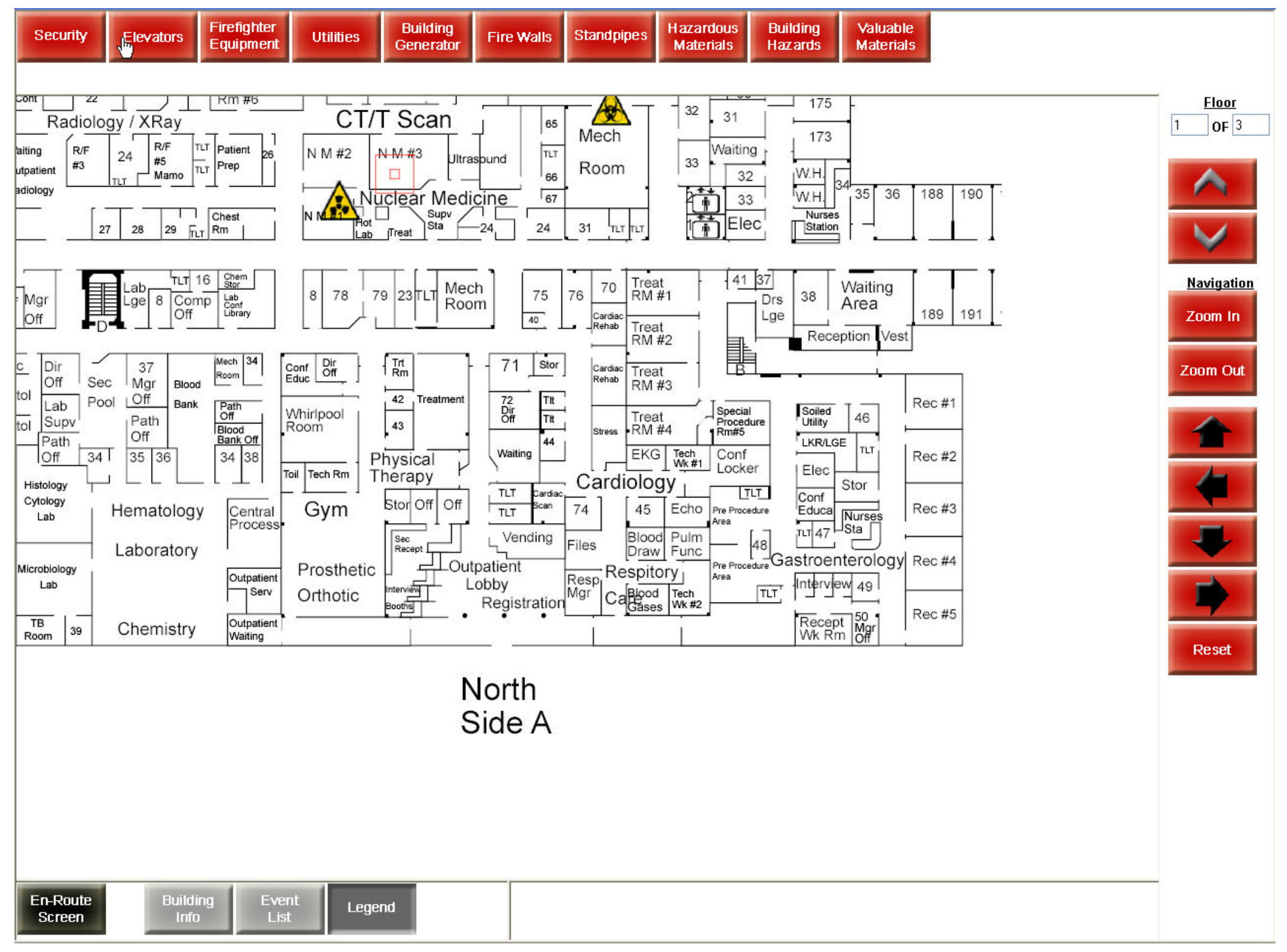

Figure 3 “On Site” screen for the hospital scenario, first floor plan zoomed in. 


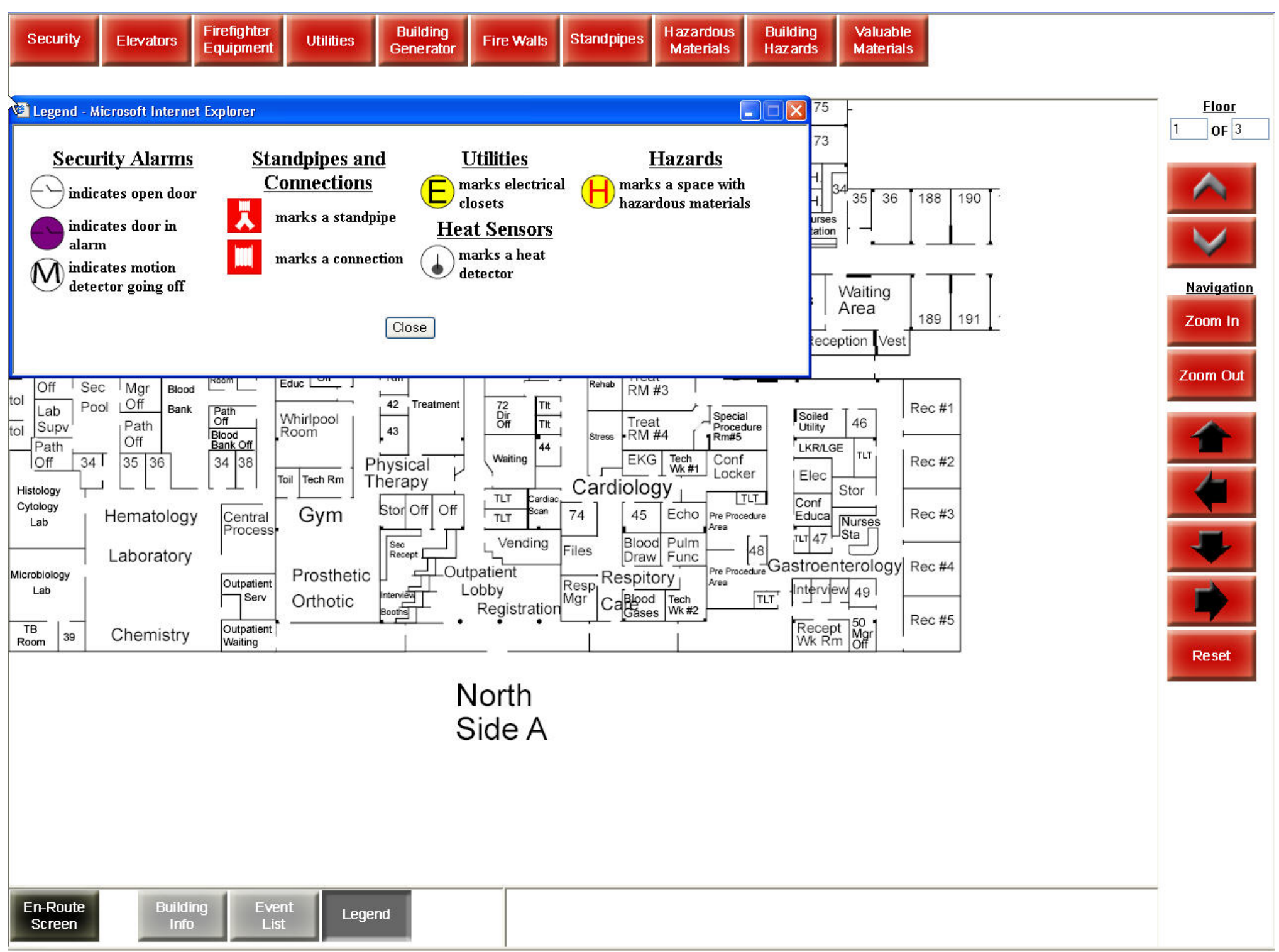

Figure 4 "On Site" screen for the hospital fire scenario, legend button activated. 


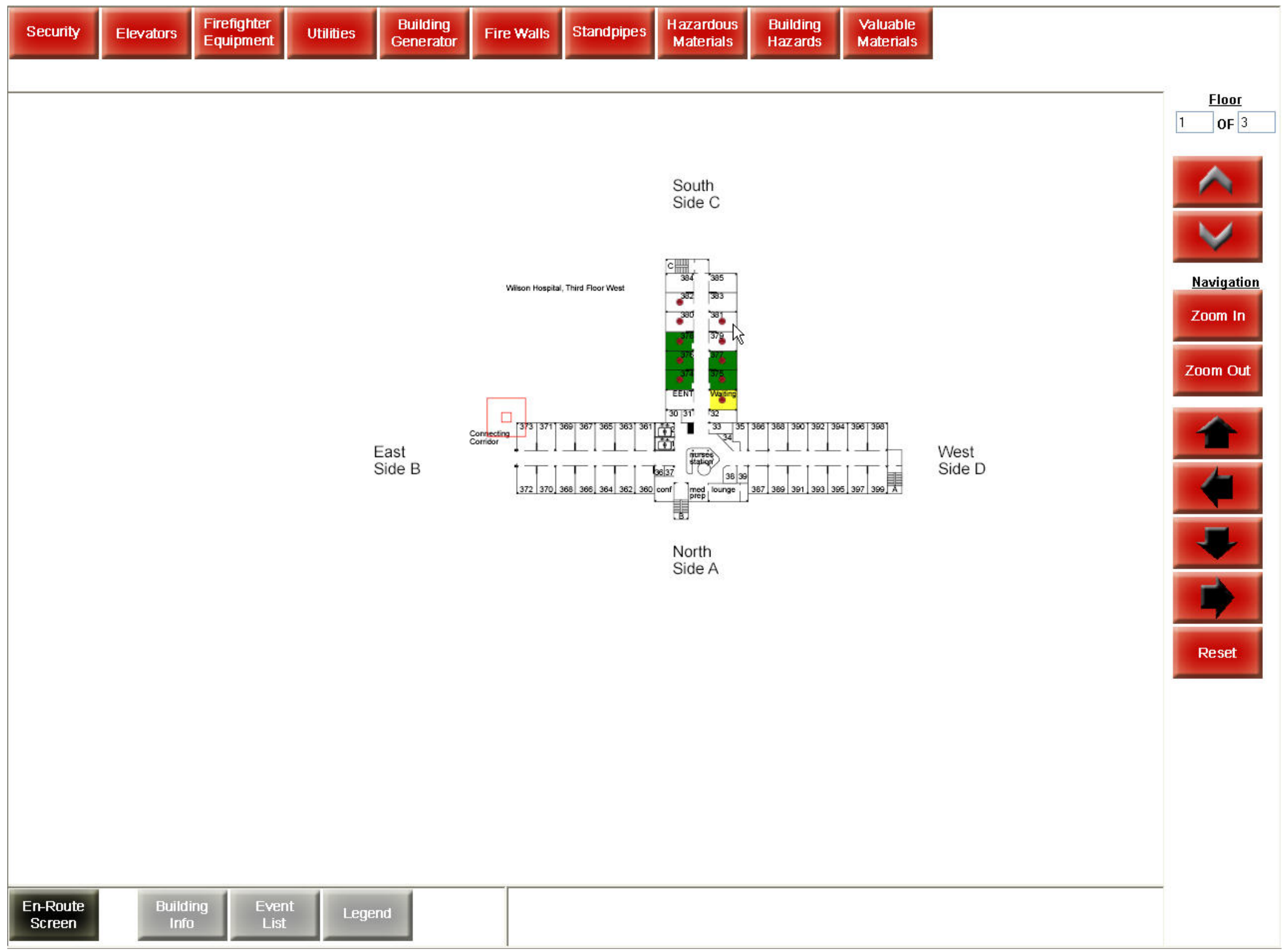

Figure 5 “On Site” screen on the hospital scenario, third floor plan. 


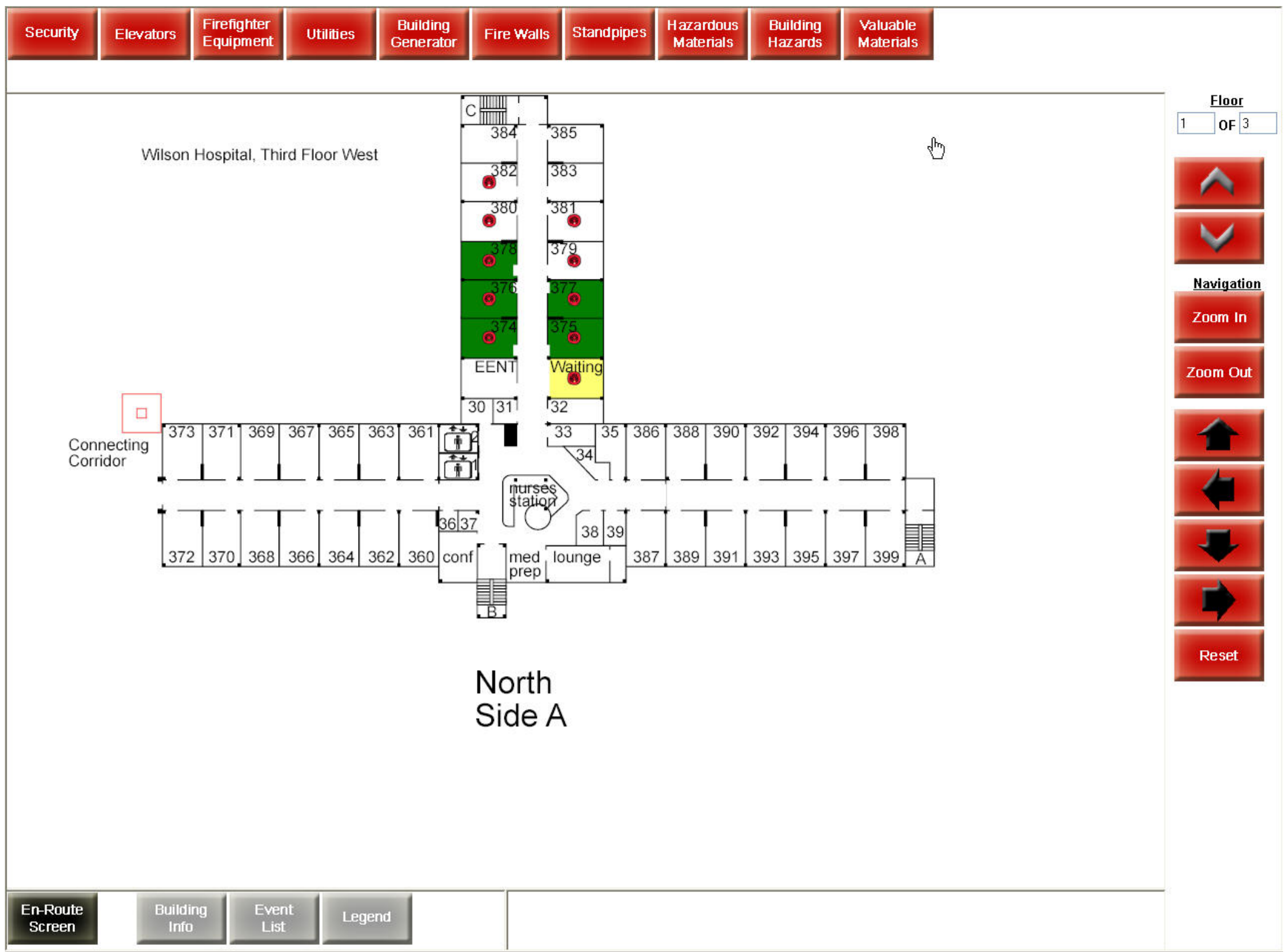

Figure 6 "On Site” screen of the hospital scenario, third floor plan zoomed in. 


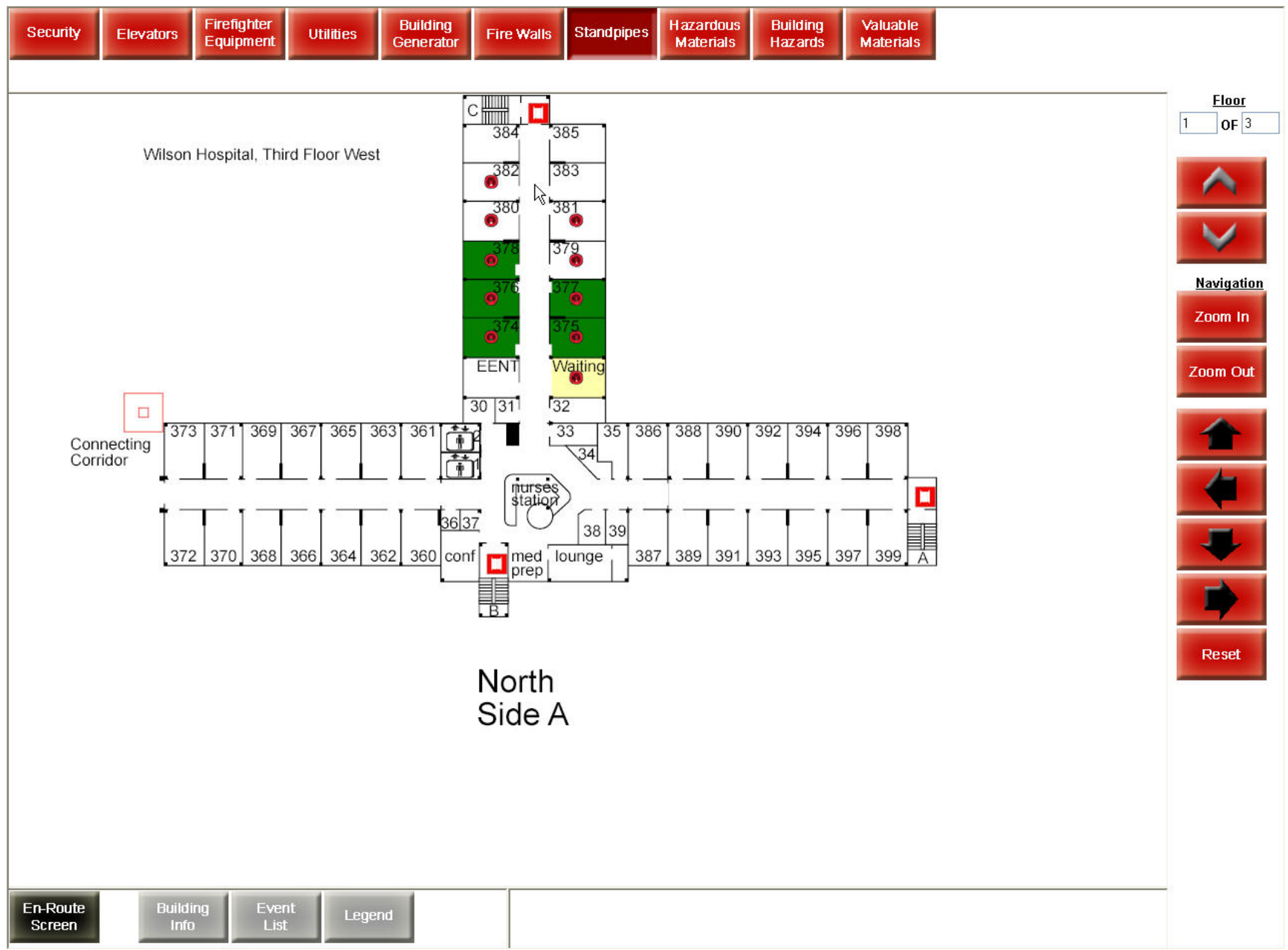

Figure 7 "On Site” screen of the hospital scenario, third floor plan zoomed in, showing interior standpipe locations in the stairwells. 


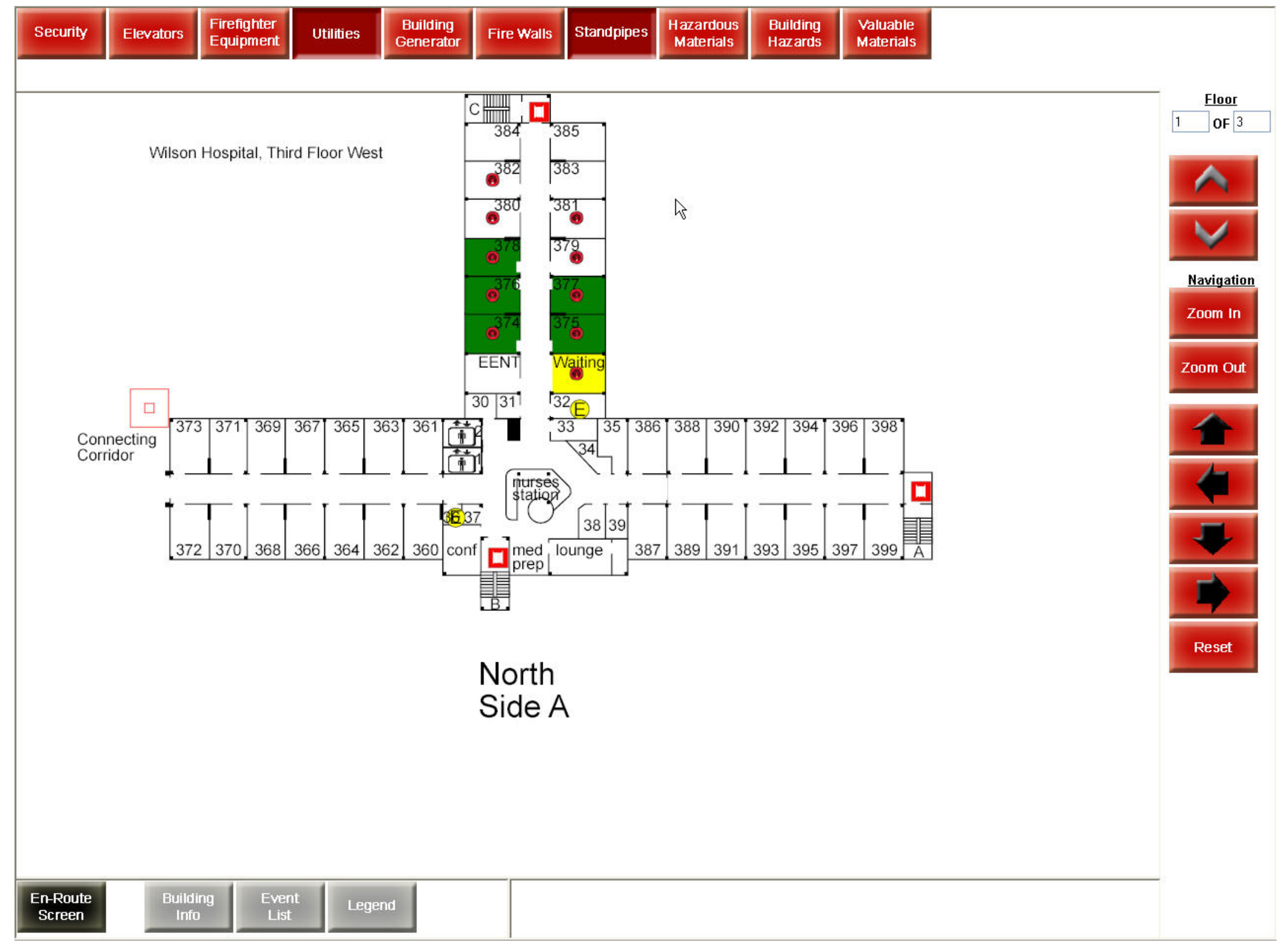

Figure 8 "On Site” screen of the hospital scenario, third floor plan zoomed in, showing interior standpipe locations in the stairwells, and location of electrical utilities. 


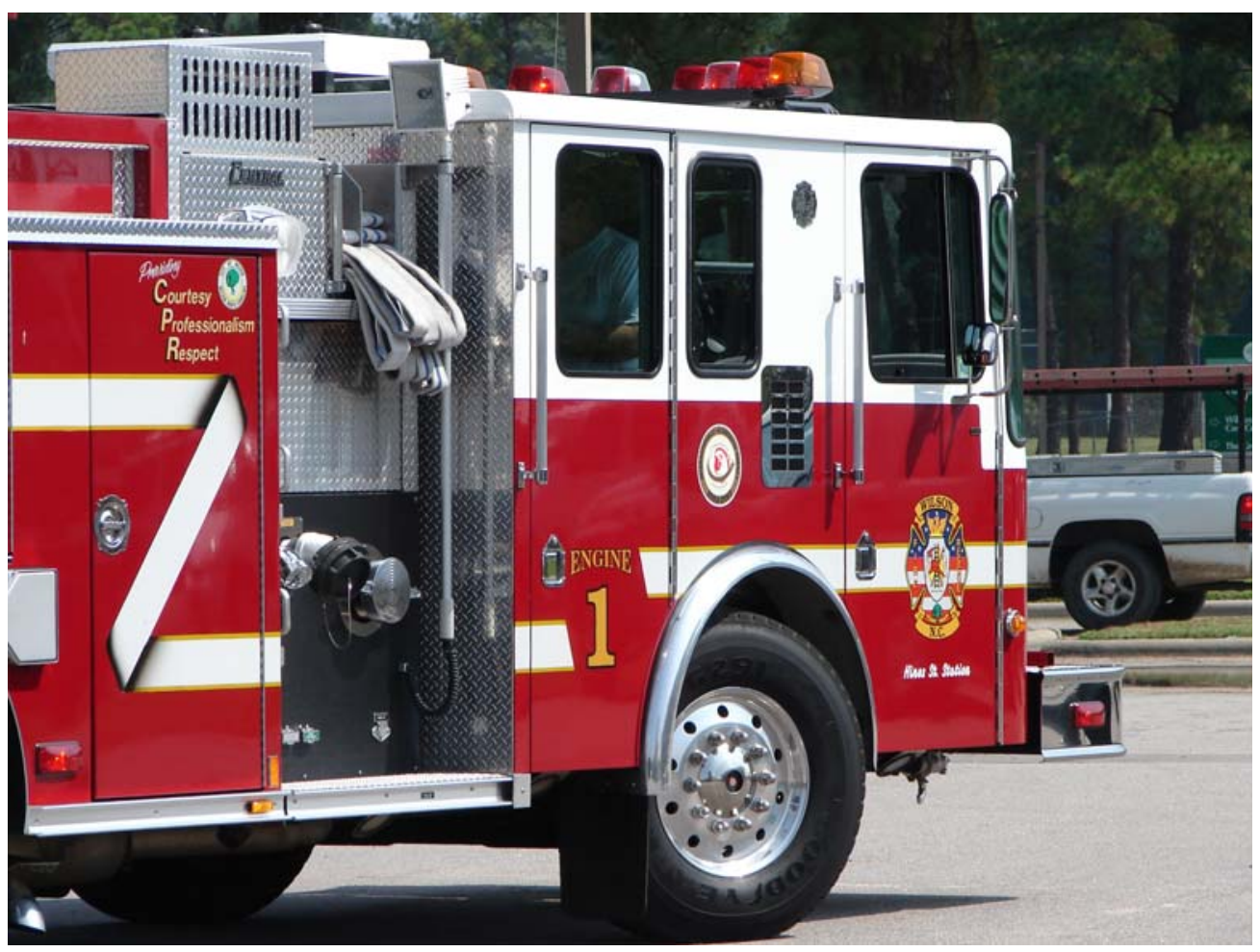

Figure 9 Fire apparatus responding to an incident.

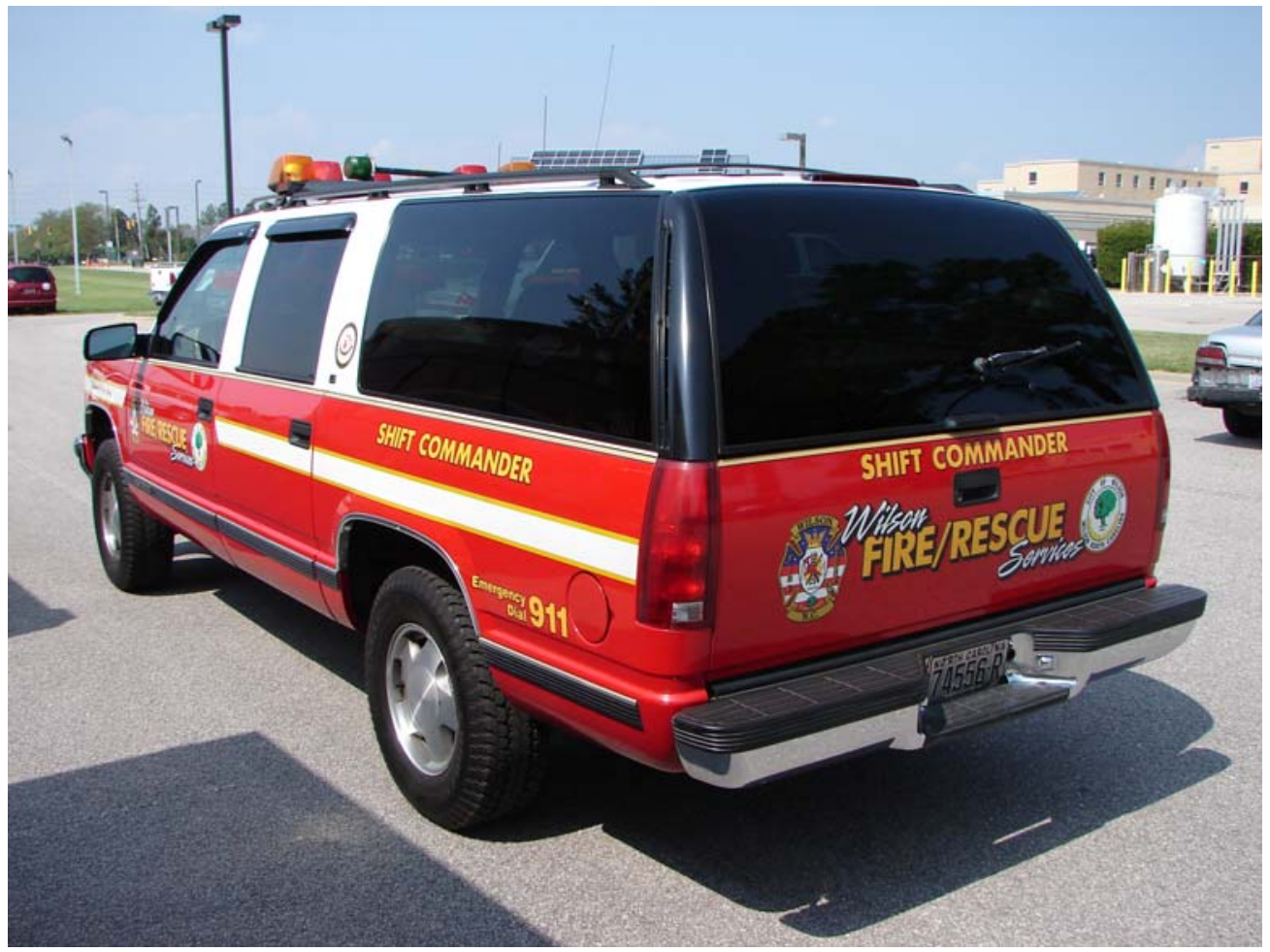

Figure 10 Chiefs vehicle. 


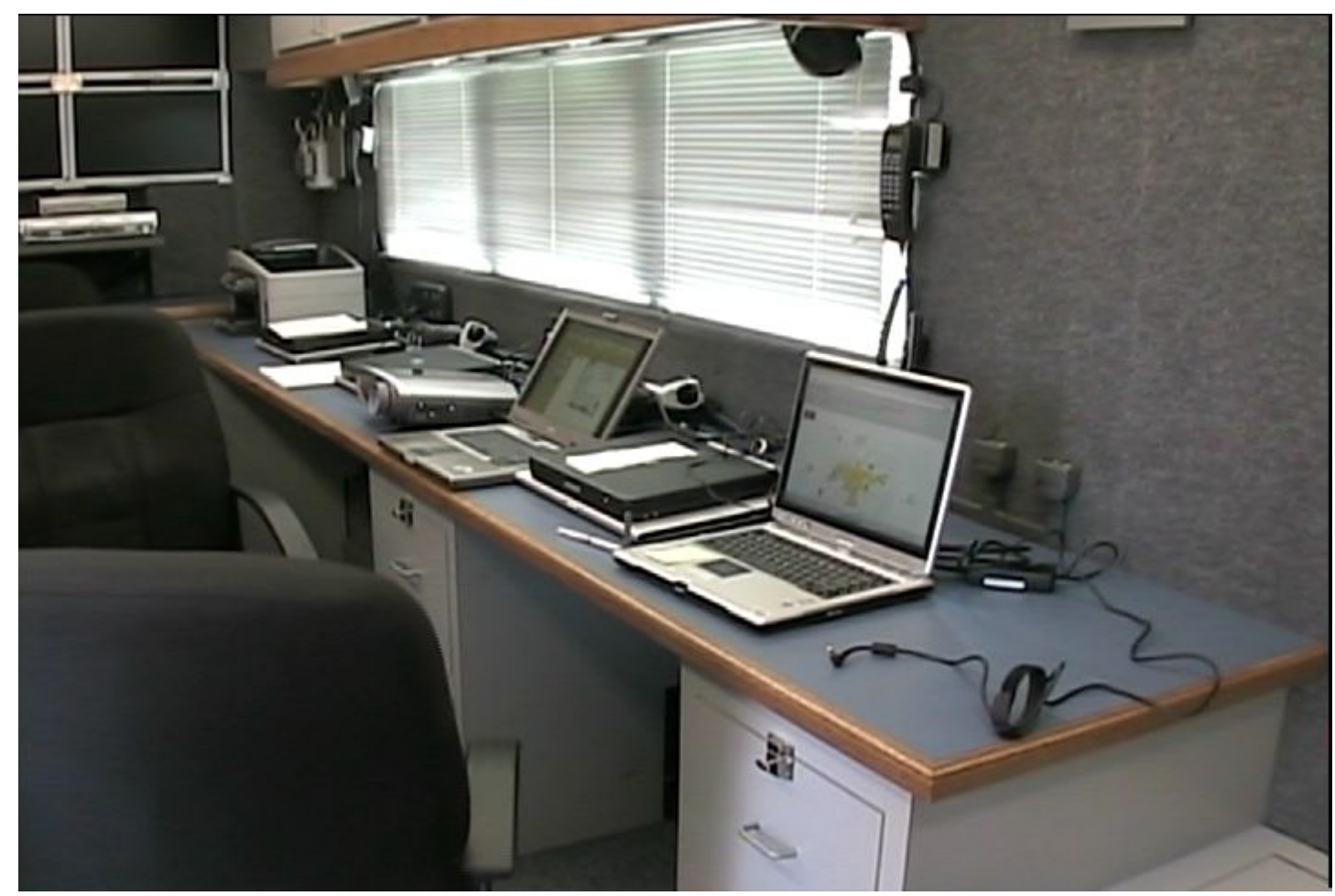

Figure 11 Interior view of incident command vehicle.

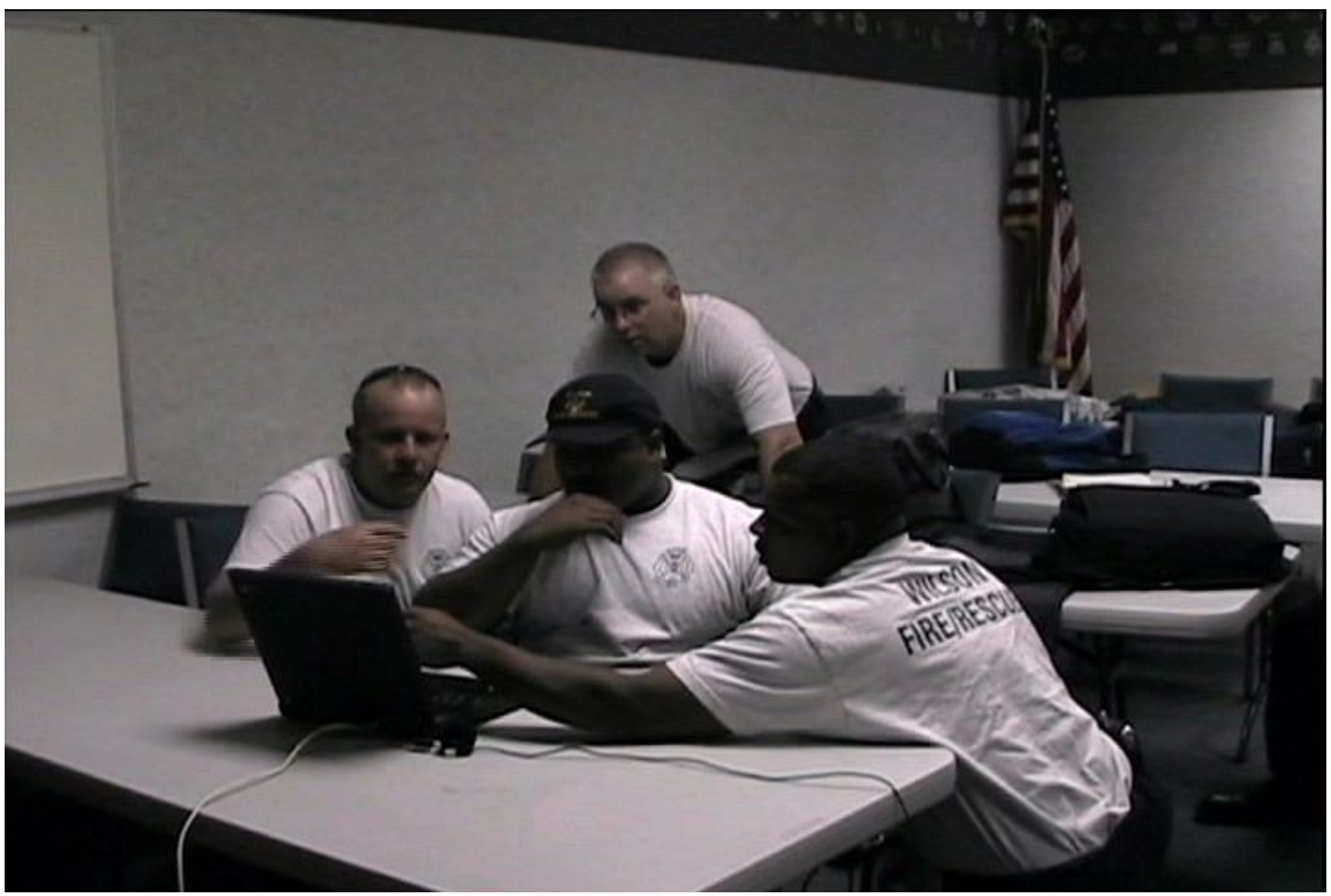

Figure 12 Fire Fighters at a remote location from the incident accessing incident information. 


\section{References}

1 "ANSI/ASHRAE Standard 135-2004 BACnet-A Data Communication Protocol for Building Automation and Control Networks", 2005

2 Jones, W., Holmberg, D., Davis, W., Evans, D., Bushby, S., and Reed, K., Workshop to Define Information Needed by Emergency Responders during Building Emergencies NISTIR 7193, National Institute of Standards and Technology, Gaithersburg, MD. January 2005.

3 National Fire Protection Association, NFPA 1620: Recommended Practice for PreIncident Planning, National Fire Protection Association, 1 Batterymarch Park, Quincy, Massachusetts, USA 02169-7471

4 Davis, W., Vettori, R., Reneke, P., Brassell, L., Holmberg, D., Kostecki, J., Kratchman, J., Workshop on the Evaluation of a Tactical Decision Aid Display, NISTIR 7268, National Institute of Standards and Technology, Gaithersburg, MD. October 2005. 